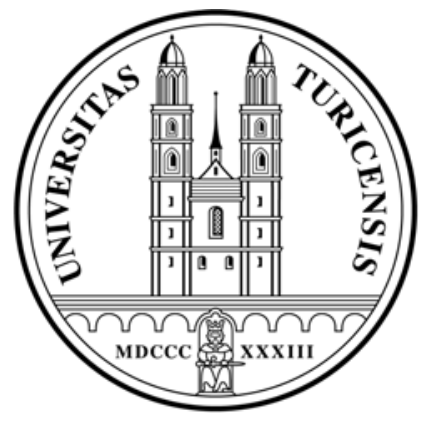

Institute for Empirical Research in Economics

University of Zurich

Working Paper Series

ISSN 1424-0459

Working Paper No. 274

Loss Aversion? Not with Half-a-Million on the Table!

Pavlo Blavatskyy and Ganna Pogrebna

March 2006 


\title{
Loss Aversion? Not with Half-a-Million on the Table!
}

\author{
Pavlo Blavatskyy ${ }^{1}$ and Ganna Pogrebna ${ }^{2}$
}

February 2006

\begin{abstract}
In the television show Affari Tuoi a contestant is endowed with a sealed box containing a monetary prize between one cent and half a million euros. In the course of the show the contestant is offered to exchange her box for another sealed box with the same distribution of possible monetary prizes inside. This offers a unique natural laboratory for testing the predictions of expected utility theory versus prospect theory using lotteries with large stakes. While expected utility theory predicts that an individual is exactly indifferent between accepting and rejecting the exchange offer, prospect theory predicts that an individual should always reject the exchange offer due to the assumption of loss aversion. We find that the assumption of loss aversion is violated by 46 percent of all contestants in our recorded sample. Thus, contestants do not appear to be predominantly loss averse when dealing with lotteries involving large stakes.
\end{abstract}

Key words: loss aversion, expected utility theory, prospect theory, natural experiment JEL Classification codes: C93, D81

\footnotetext{
${ }^{1}$ Corresponding author, Institute for Empirical Research in Economics, University of Zurich, Winterthurerstrasse 30, CH-8006 Zurich, Switzerland, tel.: +41(0)446343586, fax: +41(0)446344978, e-mail: pavlo.blavatskyy@iew.unizh.ch

${ }^{2}$ University of Innsbruck, Department of Economics, Institute of Public Finance, Universitätstrasse 15/4, A - 6020 Innsbruck, Austria, tel.: +43 (0)5125077148, email: ganna.pogrebna@uibk.ac.at
} 


\section{Loss Aversion? Not with Half-a-Million on the Table!}

\section{Introduction}

Substantial experimental evidence from economics and psychology suggests that initial endowments have an impact on human preferences. This finding precipitates an ongoing debate between two contending theories - conventional expected utility theory (Von Neumann and Morgenstern (1944)) and psychologically-driven prospect theory (Tversky and Kahneman (1979)). Early studies (e.g. Kahneman and Tversky (1979), Knetsch (1989), Kahneman, Knetsch and Thaler (1990), Tversky and Kahneman (1991) and Bateman et al. (1997)) criticize mainstream economic assumptions about preferences and argue that people are loss averse. Particularly, Tversky and Kahneman (1991) find that when comparing losses with equal-sized gains, people tend to significantly overestimate losses, setting the value of losses to the double of the value of equal-sized gains.

Tversky and Kahneman (1979) believe that the amount of current wealth is a reference point, which has an impact on human decisions in risky situations. Loss aversion implies that the value function should dramatically alter its slope at the reference point. Rabin (2000) proposes a “calibration theorem”, which shows that a concave utility function, assumed by expected utility theory, fails to capture this effect. He argues that loss aversion can be fully explained by expected utility theory only if the concave utility function is assumed to have a kink around the reference point.

According to Rabin (1998), endowment effect and status quo bias are two phenomena, closely related to loss aversion. Endowment effect (Thaler (1980)) says that when people come to own a good, they tend to value it more than they did before they owned it (Kahneman, Knetsch and Thaler (1991)). For example, Kahneman, Knetsch and Thaler (1990) find that students, who were given mugs worth 5 USD each, were willing 
to sell them at an average price of 7 USD each. At the same time, students, who did not come to possess the mugs, were willing to buy them at an average price of 3.50 USD per mug. While many experiments replicate this result, several studies treat endowment effect as essentially an inexperienced consumer's mistake, which disappears in the process of learning (e.g. Knez, Smith and Williams (1985), Coursey, Hovis and Schulze (1987), Brookshire and Coursey (1987), Shogren et al. (1994)).

Status quo bias emerges when an individual faces a choice between several goods (Kahneman, Knetsch and Thaler (1991)). In this case, a loss averse individual opts for maintaining the status quo as opposed to making decisions that may lead to the loss of a good, even if this loss is compensated by a gain of another good (Rabin (1998)). According to Knetsch and Sinden (1984), Samuelson and Zeckhauser (1988) and Knetsch (1989) 90 percent of students, initially endowed with a mug (candy bar), are not willing to exchange it for candy bar (mug).

List (2004) has conducted a similar experiment with ordinary consumers and professsional dealers on the sportscard market. In this field experiment he finds that while trades are infrequent among inexperienced consumers, professional dealers are more likely to accept the exchange offer. List (2004) argues that when consumers face decision problem, which they have never experienced before, they may overcome the endowment effect. In a similar vein, Myagkov and Plott (1997) find that risk-seeking behavior over losses, predicted by prospect theory, tends to decrease with experience in a market setting. We use the natural laboratory of Italian television show Affari Tuoi ${ }^{3}$ to analyze the effects of loss aversion, when stakes are large. Affari Tuoi is the Italian version of the television show Deal or No Deal, produced at different times by the media company

\footnotetext{
${ }^{3}$ In translation from Italian "Your Business", "Your Affairs".
} 
Endemol in 26 countries worldwide. In Affari Tuoi a contestant is assigned a sealed box, containing a monetary prize between 0.01 to 500,000 EUR. At least once during the television episode, a contestant is offered to exchange her box for another box, which contains the same distribution of possible monetary prizes. ${ }^{4}$ This provides a unique opportunity to test the assumption of loss aversion in a previously unexplored domain when lotteries involve large outcomes (up to half a million euros). Since two boxes that may be exchanged contain the same distribution of monetary prizes, a loss averse contestant should always reject the exchange offer. ${ }^{5}$ In contrast, an expected utility maximizer is exactly indifferent between accepting and rejecting the exchange offer.

Several studies use natural experiments to draw conclusions about economic behavior. Structured as well-defined decision problems or strategic games, television shows provide an interesting research material for economic theorists (Metrick (1995)). Particularly, using data from the television show The Prize is Right, Bennett and Hickman (1993) and Berk, Hughson and Vandezande (1996) test for the optimal information updating and rational bidding strategies correspondingly. Gertner (1993), Metrick (1995), and Beetsma and Schotman (2001) employ the natural laboratories of Card Sharks, Jeopardy! and Lingo television shows respectively to measure individual risk attitudes. Levitt (2004) and Antonovics, Arcidiancono and Walsh (2005) examine discrimination in The Weakest Link. Bombardini and Trebbi (2005) attempt to elicit risk attitudes of Affari Tuoi contestants from their decisions on the last three monetary offers.

\footnotetext{
${ }^{4}$ In addition to exchange offers, contestants also receive monetary offers for selling the content of their box.

${ }^{5}$ Notice that this is a stronger implication of loss aversion than in the mug-candy bar exchange experiments (List (2004)). In exchange experiments loss aversion implies that the fraction of individuals, who are not willing to exchange a mug (candy bar) for a candy bar (mug), should be higher in the treatment where subjects were initially endowed with a mug (candy bar) compared to the fraction of subjects in the baseline treatment, who were endowed with nothing and subsequently choose a mug (candy bar). Such control treatment is not required in our natural experiment because two objects that may be exchanged yield identical distributions of monetary prizes.
} 
Post, Baltussen and Van den Assem (2006) analyze risk attitudes of Dutch and Australian contestants using the natural laboratory of Deal or No Deal.

The remainder of this paper is organized as follows. Section 2 describes the television show Affari Tuoi. Section 3 presents the basic statistics about our recorded sample of television episodes. Section 4 derives the theoretical predictions of expected utility theory and prospect theory. Section 5 relates the theoretical prediction to the observed decisions of the contestants. Section 6 concludes.

\section{Description of the Game}

Affari Tuoi is a daily television show, broadcasted on the first channel of Italian television RAI Uno. Contestants of Affari Tuoi self-select into the show by calling the countrywide selection center. Twenty contestants participate in every episode. Each contestant represents one of twenty Italian administrative regions. Every contestant is randomly assigned one box that contains one of twenty monetary prizes ranging from 0.01 to 500,000 EUR. The list of possible prizes is presented in Table 1. All boxes are sealed by an independent notary company and are numbered consecutively from 1 to 20 . Contestants know the list of possible prizes i.e. Table 1 but they do not know the content of each box.

Table 1 Twenty possible prizes (in EUR)

\begin{tabular}{|c|c|c|c|}
\hline 0.01 & 10 & $5000^{6}$ & 50000 \\
\hline 0.2 & 50 & 10000 & 75000 \\
\hline 0.5 & 100 & 15000 & 100000 \\
\hline 1 & 250 & 20000 & 250000 \\
\hline 5 & 500 & 25000 & 500000 \\
\hline
\end{tabular}

In the beginning of each television episode contestants receive one general knowledge question with three possible answers (A, B and C). The contestant, who is the

\footnotetext{
${ }^{6}$ Prize 5000 Euro was replaced with prize 30000 Euro starting from January 30, 2006
} 
first to answer this question correctly, is selected to play the game. ${ }^{7}$ During the game, the contestant keeps her own box and opens the remaining boxes one by one. When a box is opened, the prize hidden inside is publicly revealed and it is erased from the list of possible prizes.

After opening several boxes the contestant receives an offer from the "bank". The offer could be either a monetary price for the content of her box or the possibility to exchange her box for any of the remaining sealed boxes. Like contestants, the "bank" does not know which prize is hidden inside each box.

In this paper we analyze the decisions of contestants when they are offered to exchange boxes. In every episode, the contestant receives at least one offer to exchange her box (typically after opening six boxes ${ }^{8}$ ). Occasionally, the contestant also receives the second offer to exchange her box (typically when there are only two sealed boxes left ${ }^{9}$ ). The game terminates when either the contestant accepts the price offered by the "bank" or when all boxes are opened. In the latter case, the contestant leaves with the content of her box, which is opened last.

\section{Basic Statistics}

The natural laboratory of Affari Tuoi, analyzed in this paper, incorporated one hundred television episodes, broadcasted on RAI Uno from September 20, 2005 to February 14, 2006. The data were transcribed from original television broadcasts.

\footnotetext{
${ }^{7}$ The remaining 19 contestants continue to participate in the next television episode. The contestant who was selected to play the game is replaced by a new contestant from the same region. New contestant is selected from a pool of volunteers who called the selection center.

${ }^{8}$ Official rules of the show require the "bank" to offer exchange option at least once in every television episode. Therefore, the first offer that the "bank" makes is always the exchange offer. Before February 11, 2006, the first offer was always made after the contestant opened six boxes. Starting from February 11, 2006, the first offer is made after the contestant opened three boxes.

${ }^{9}$ Including the box in the possession of the contestant.
} 
Contestants, aged from 23 to $70^{10}$, from all regions of Italy participated in the show (Figure 1). An overwhelming majority of contestants (81 percent ) were married, 13 percent — single, 4 percent — divorced and 2 percent — widowed. 45 percent of Affari Tuoi contestants were male and 55 percent were female. Thus, this natural experiment relied on a more representative subject pool than the conventional laboratory experiments.

\section{[INSERT FIGURE 1 HERE]}

On average, contestants earned 30,363 EUR, with the standard deviation of 43,815 EUR (the median earnings in the sample amounted to 20,000 EUR). Thus, actual average earnings in the show fall short of the ex ante expected value of the prizes from Table 1, which is 52,295 EUR. Average final earnings were also lower than the average prize in the boxes initially assigned to the contestants who played the game. Figure 2 shows the distribution of monetary prizes that were initially allocated to the contestants who played the game in one hundred episodes in our sample. This distribution is not significantly different from a uniform distribution $\left(\chi^{2}=21.20, p=0.3259\right)$. Average initial endowment amounted to 39,096 EUR and median initial endowment was 250 EUR.

\section{[INSERT FIGURE 2 HERE]}

The minimum prize earned in our sample was 0.01 EUR and the maximum prize was 250,000 EUR. Figure 3 depicts the distribution of final prizes, earned by contestants across one hundred Affari Tuoi television episodes. Obviously, replicating this natural experiment in conventional laboratory conditions would be a highly challenging task, since it would require a budget of at least 3,036,332 EUR. Men won on average 946 EUR

\footnotetext{
${ }^{10}$ Sometimes contestants do not reveal their age. The reported minimum and maximum age are derived from the subsample of contestants who specified their age during the show.
} 
more than women (median earnings were 20,000 EUR both for male and female). However, standard deviation for final prizes, received by men, was 12,332 EUR higher than that for final prizes, won by women.

\section{[INSERT FIGURE 3 HERE]}

\section{Theoretical prediction}

According to expected utility theory, an individual should be exactly indifferent between keeping her box and exchanging it for any of the remaining sealed boxes. Consider a contestant who is offered an exchange when there are $N$ sealed boxes each containing one of the prizes $x_{1}<x_{2}<\ldots<x_{N}$. If an individual keeps her box, she obtains expected utility $\frac{1}{N} \sum_{i=1}^{N} u\left(w+x_{i}\right)$, where $u($.$) is a von Neumann-Morgenstern utility$ function of the contestant and $w$ is her private wealth.

If the contestant exchanges her box that contains prize $x_{i}, i \in\{1, \ldots, N\}$, for one of the remaining sealed boxes, she obtains expected utility $\frac{1}{N-1} \sum_{\substack{j=1 \\ j \neq i}}^{N} u\left(w+x_{j}\right)$. The contestant does not know the content of her box and any prize $x_{1}, \ldots, x_{N}$ is equally likely to be inside her box. Therefore, after exchanging the boxes, the contestant receives expected utility $\frac{1}{N} \sum_{i=1}^{N} \frac{1}{N-1} \sum_{\substack{j=1 \\ j \neq i}}^{N} u\left(w+x_{j}\right)=\frac{1}{N(N-1)} \sum_{i=1}^{N}\left(\sum_{j=1}^{N} u\left(w+x_{j}\right)-u\left(w+x_{i}\right)\right)=$ $=\frac{1}{N} \sum_{i=1}^{N} u\left(w+x_{i}\right)$. Thus, the contestant receives exactly the same expected utility after exchanging her box as after keeping her initial box. In other words, according to expected utility theory there is no reason why the contestant should except or reject an offer to exchange her box for one of the remaining sealed boxes. 
In contrast, according to prospect theory an individual should never exchange her own box for any of the remaining sealed boxes due to the assumption of loss aversion. In prospect theory, an individual derives utility from changes in wealth rather than from absolute wealth levels. Utility from changes in wealth is captured by the value function $v($.$) which is normalized so that v(0)=0$. Individuals are assumed to be loss averse so that the value function is steeper for losses than for gains i.e. $v(x)<-v(-x)$ for any $x>0$ (Kahneman and Tversky (1979)). Thus, if an individual keeps her own box, she obtains utility $v(0)=0$ because her wealth remains unchanged.

Now consider an individual who exchanges her own box with prize $x_{i}$ for a box with a lower prize $x_{j}, j \in\{1, \ldots, i-1\}$. According to the cumulative prospect theory, this exchange yields utility $\sum_{j=1}^{i-1} v\left(x_{j}-x_{i}\right) \cdot\left[w_{-}\left(\operatorname{prob}\left(\delta \leq x_{j}-x_{i}\right)\right)-w_{-}\left(\operatorname{prob}\left(\delta<x_{j}-x_{i}\right)\right)\right]$, where $w_{-}:[0,1] \rightarrow[0,1]$ is the probability weighting function for losses (Tversky and Kahneman (1992)) and $\operatorname{prob}\left(\delta<x_{j}-x_{i}\right)$ denotes the probability that the change in individual's wealth $\delta$ during the exchange of the boxes is lower than $x_{j}-x_{i}$.

Finally, consider an individual who exchanges her own box with prize $x_{i}$ for a box with a higher prize $x_{j}, j \in\{i+1, \ldots, N\}$. According to the cumulative prospect theory this individual obtains utility $\sum_{j=i+1}^{N} v\left(x_{j}-x_{i}\right) \cdot\left[w_{+}\left(\operatorname{prob}\left(\delta \geq x_{j}-x_{i}\right)\right)-w_{+}\left(\operatorname{prob}\left(\delta>x_{j}-x_{i}\right)\right)\right]$, where $w_{+}:[0,1] \rightarrow[0,1]$ is the probability weighting function for gains. The contestant does not know the prize $x_{i}$ sealed inside her box. Thus, her ex ante utility from exchanging the boxes is given by $U=\sum_{i=1}^{N} \sum_{j=1}^{i-1} v\left(x_{j}-x_{i}\right) \cdot\left[w_{-}\left(\operatorname{prob}\left(\delta \leq x_{j}-x_{i}\right)\right)-w_{-}\left(\operatorname{prob}\left(\delta<x_{j}-x_{i}\right)\right)\right]+$ $+\sum_{i=1}^{N} \sum_{j=i+1}^{N} v\left(x_{j}-x_{i}\right) \cdot\left[w_{+}\left(\operatorname{prob}\left(\delta \geq x_{j}-x_{i}\right)\right)-w_{+}\left(\operatorname{prob}\left(\delta>x_{j}-x_{i}\right)\right)\right]$ or, equivalently, by 


$$
\begin{array}{r}
U=\sum_{i=1}^{N} \sum_{j=1}^{i-1}\left\{v\left(x_{j}-x_{i}\right) \cdot\left[w_{-}\left(\operatorname{prob}\left(\delta \leq x_{j}-x_{i}\right)\right)-w_{-}\left(\operatorname{prob}\left(\delta<x_{j}-x_{i}\right)\right)\right]+\right. \\
\left.+v\left(x_{i}-x_{j}\right) \cdot\left[w_{+}\left(\operatorname{prob}\left(\delta \geq x_{i}-x_{j}\right)\right)-w_{+}\left(\operatorname{prob}\left(\delta>x_{i}-x_{j}\right)\right)\right]\right\}
\end{array}
$$

Since all prizes are randomly distributed across the boxes, when two boxes are exchanged, every positive change in wealth is equally likely as a negative change in wealth of the same absolute amount. In other words, $\operatorname{prob}\left(\delta \geq x_{i}-x_{j}\right)=\operatorname{prob}\left(\delta \leq x_{i}-x_{j}\right)$ and $\operatorname{prob}\left(\delta>x_{i}-x_{j}\right)=\operatorname{prob}\left(\delta<x_{i}-x_{j}\right)$ for every $x_{j}<x_{i}$. Assumption of loss aversion additionally implies that $v\left(x_{i}-x_{j}\right)<-v\left(x_{j}-x_{i}\right)$ for every $x_{j}<x_{i}$. Using these two results we can rewrite equation (1) as an inequality

$$
\begin{array}{r}
U<\sum_{i=1}^{N} \sum_{j=1}^{i-1} v\left(x_{j}-x_{i}\right) \cdot\left[w_{-}\left(\operatorname{prob}\left(\delta \leq x_{j}-x_{i}\right)\right)-w_{-}\left(\operatorname{prob}\left(\delta<x_{j}-x_{i}\right)\right)-\right. \\
\left.-w_{+}\left(\operatorname{prob}\left(\delta \leq x_{j}-x_{i}\right)\right)+w_{+}\left(\operatorname{prob}\left(\delta<x_{j}-x_{i}\right)\right)\right]
\end{array}
$$

Previous experimental studies demonstrate that the probability weighting function is "essentially the same" for gains and losses (e.g. Tversky and Kahneman (1992), Abdellaoui (2000)). Assuming that $w_{+}(p)=w_{-}(p)$ for every $p \in[0,1]$, inequality (2) immediately implies that $U<0$ i.e. the contestant derives a strictly negative utility from exchanging her box for one of the remaining sealed boxes. In other words, according to prospect theory an individual has a strong reason not to exchange her box: the value of exchange is strictly negative because a loss averse individual expects more aggravation from losses than the pleasure from gains of the same amount.

\section{Results}

The theoretical analysis in the previous section critically relies on the assumption that the monetary prizes from Table 1 are distributed in a random order across the boxes. Although this is explicitly stated in the rules of the television show, we verified within our recorded sample if every prize indeed appeared to be equally likely to be inside any 
of twenty boxes. In other words, we checked whether contestants in our sample had an apparent reason to believe that the prizes were not randomly distributed.

Figures 4 and 5 show how many times every prize was sealed inside each box across 100 television episodes. For all prizes, this actual distribution is not significantly different from a uniform distribution (when every prize appears exactly five times inside each box) at 1 percent significance level. This also holds for all prizes except for 50 EUR and 500 EUR at 5 percent significance level (the results of the chi-squared test are presented on Figures 4 and 5). ${ }^{11}$ Thus, contestants in our sample did not have any apparent reason to suspect that some prizes were more likely to be inside particular $\operatorname{box}(\mathrm{es})$.

\section{[INSERT FIGURES 4 AND 5 HERE]}

In every episode within our sample of observations, a contestant received either one or two offers to exchange her box. In 98 percent of all episodes the first (or the only) exchange offer was made after the contestant opened six boxes. ${ }^{12}$ In 27 percent of all episodes a contestant received two offers to exchange her box. In 74 percent of all cases when the "bank" made the second exchange offer, it was made when there were only two unopened boxes left (including the box in the possession of the contestant). ${ }^{13}$

Tables 2 and 3 summarize the decisions of contestants on the first (or the only) exchange offer and the second exchange offer correspondingly. The first (or the only) exchange offer was accepted in 39 percent of all cases and the second exchange offer was

\footnotetext{
${ }^{11}$ We also checked the distribution of prizes across twenty administrative regions of Italy whose representatives were initially endowed with the boxes. For all prizes we were unable to reject the hypothesis that the distribution across regions is not significantly different from a uniform distribution at 5 percent significance level.

${ }^{12}$ In the remaining two percent of all episodes the "bank" made the first and the only exchange offer when three boxes where opened.

${ }^{13}$ In 19 percent of the cases the second exchange offer was made when five unopened boxes were left. In 7 percent of the cases, the second exchange offer was made when there were eight unopened boxes left.
} 
accepted in 37 percent of all cases. Overall in our sample, accepting the exchange offer appears to be slightly more rewarding than rejecting the offer. The median prize inside unopened boxes excluding the box in the possession of the contestant was higher than the prize inside the contestant's box in 57 percent of all cases when the first (or the only) exchange offer was made and in 56 percent of all cases when the second exchange offer was made. Ex post, contestants who actually switched the boxes performed even better than their slightly more favorable statistical odds. The prize in the new box after the exchange was higher than the prize in the old box before the exchange in 67 percent of all cases when the first (or the only) exchange offer was accepted and in 70 percent of all cases when the second exchange offer was accepted.

Table 2 Decisions of contestants on the first (or only) exchange offer $(\mathrm{N}=100)$

\begin{tabular}{|c|c|c|c|}
\hline \multirow{2}{*}{$\begin{array}{c}\text { First (or only) } \\
\text { exchange offer }\end{array}$} & \multicolumn{3}{|c|}{ Number (percentage) of episodes } \\
\cline { 2 - 4 } & Total & $\begin{array}{c}\text { Median prize in other } \\
\text { boxes exceeds prize in } \\
\text { own box before exchange }\end{array}$ & $\begin{array}{c}\text { Prize in new box after } \\
\text { exchange exceeds prize in } \\
\text { old box before exchange }\end{array}$ \\
\hline Accepted & $39(39 \%)$ & $22(56 \%)$ & $26(67 \%)$ \\
\hline Rejected & $61(61 \%)$ & $35(57 \%)$ & \\
\hline
\end{tabular}

Table 3 Decisions of contestants on the second exchange offer $(N=27)$

\begin{tabular}{|c|c|c|c|c|}
\hline \multirow{2}{*}{$\begin{array}{c}\text { First } \\
\text { exchange } \\
\text { offer }\end{array}$} & $\begin{array}{c}\text { Second } \\
\text { exchange } \\
\text { offer }\end{array}$ & Total & $\begin{array}{c}\text { Number (percentage) of episodes } \\
\text { Median prize in other } \\
\text { boxes exceeds prize in } \\
\text { own box before exchange }\end{array}$ & $\begin{array}{c}\text { Prize in new box after } \\
\text { exchange exceeds prize in } \\
\text { old box before exchange }\end{array}$ \\
\cline { 3 - 5 } Accepted & Accepted & $3(11 \%)$ & $1(33 \%)$ & $1(33 \%)$ \\
\cline { 2 - 5 } & Rejected & $8(30 \%)$ & $4(50 \%)$ & $6(86 \%)$ \\
\hline \multirow{2}{*}{ Rejected } & Accepted & $7(26 \%)$ & $6(86 \%)$ & \\
\cline { 2 - 5 } & Rejected & $9(33 \%)$ & $4(44 \%)$ & \\
\hline
\end{tabular}

High percentage of contestants, who exchange their boxes and do not keep their initial endowment, directly contradicts to the prediction of the cumulative prospect 
theory. The assumption of loss aversion is violated by 46 percent of all contestants in our sample (who accepted at least one exchange offer). Thus, contestants do not appear to be predominantly loss averse when dealing with large-stake lotteries.

Expected utility theory predicts that an individual is exactly indifferent between accepting and rejecting the exchange offer. Thus, we can expect that among contestants, who received only one exchange offer, the percentage of individuals who accepted the offer is not significantly different from 50 percent. Similarly, among contestants, who received two exchange offers, the percentage of individuals who accepted both offers, rejected both offers, accepted only the first offer and accepted only the second offer should not significantly differ from 25 percent.

The corresponding chi-squared statistics is $\chi^{2}=3.959(p=0.0466)$ for contestants who received only one exchange offer and $\chi^{2}=3.074(p=0.3803)$ for contestants who received two exchange offers. Thus, the hypothesis that contestants are equally likely to accept or reject the exchange offer cannot be rejected at 1 percent significance level and it is only marginally rejected at 5 percent significance level for contestants who received only one exchange offer. In other words, the decisions of contestants of Affari Tuoi appear to be consistent with the prediction of expected utility theory.

\section{Conclusion}

Television show Affari Tuoi offers a unique opportunity to research individual decision making under risk using large-stake lotteries with outcomes as high as half a million euros. Perhaps for the first time since the famous thought experiment of Maurice Allais, we have an opportunity to study choice between large-stake lotteries with real incentives and real people. Risky lotteries are presented to Affari Tuoi contestants in a clear and transparent manner as a list of equiprobable outcomes so that the chances of 
misperception are minimal. Contestants themselves come from all regions of Italy, being widely dispersed in terms of age and occupation, which makes them a more diversified subject pool compared to the undergraduate students in the conventional laboratory experiments.

In this paper we analyze the decisions of Affari Tuoi contestants when they are offered to exchange their initial endowment for an identical lottery that yields the same distribution of possible monetary prizes. While neoclassical expected utility theory predicts that an individual should be exactly indifferent about this exchange, psychologically-driven prospect theory predicts that a loss averse individual should always keep her initial endowment. Both theories make clear and distinct predictions that can be easily tested in our natural laboratory.

We find that 46 percent of all contestants in our recorded sample violated the assumption of loss aversion by accepting the exchange offer at least once. Apparently, the contestants are not overwhelmingly loss averse when choosing between large-stake lotteries even though the potential loss during the swap might be as high as 499,999.99 EUR. We also find that the decisions of Affari Tuoi contestants are essentially consistent with the prediction of expected utility theory. These results suggest that apparently inexperienced individuals manage to overcome the effect of loss aversion when dealing with an unusual decision problem involving substantial monetary rewards. 


\section{References}

Abdellaoui, M. (2000): "Parameter-Free Elicitation of Utility and Probability Weighting Functions,” Management Science, 46, 1497-1512.

Antonovics, K., P. Arcidiancono, and R. Walsh (2005): "Games and Discrimination: Lessons From The Weakest Link,” Journal of Human Resources, 40(4), 918-947.

Bateman, I., A. Munro, B. Rhodes, C. Starmer, and R. Sugden (1997): "A Theory of Reference-Dependent Preferences,” Quarterly Journal of Economics, 112, 479-505.

Beetsma, R. M. and P.C. Schotman (2001): "Measuring Risk Attitudes in a Natural Experiment: Data from the Television Game Show Lingo,” Economic Journal, 111(474), 821-848.

Bennett, R.W. and K. A. Hickman (1993): "Rationality and 'The Price Is Right'," Journal of Economic Behavior and Organization, 21(1), 99-105.

Berk, J. B., E. Hughson and K. Vandezande (1996): "The Price Is Right, But Are the Bids? An Investigation of Rational Decision Theory,” American Economic Review, 86(4), 954-970.

Bombardini, M. and F. Trebbi (2005): "Risk Aversion and Expected Utility Theory: A Field Experiment with Large and Small Stakes," Unpublished manuscript, accessed at http://www.people.fas.harvard.edu/ trebbi/BT_17nov2005.pdf on 20.02.2006

Brookshire, D., and D. Coursey (1987): "Measuring the Value of a Public Good: An Empirical Comparison of Elicitation Procedures," American Economic Review, 77, 554566.

Coursey, D., J. Hovis, and W. Schulze (1987): “The Disparity Between Willingness to Accept And Willingness to Pay Measures of Value," Quarterly Journal of Economics, 102, 679-690.

Gertner, R. (1993): "Game Shows and Economic Behavior: Risk Taking on 'Card Sharks',” Quarterly Journal of Economics, 108(2), 507-522.

Kahneman D., J. L. Knetsch, and R. H. Thaler (1990): "Experimental Tests of the Endowment Effect and the Coase Theorem,” Journal of Political Economy, 98, 25-48.

Kahneman D., J. L. Knetsch, and R. H. Thaler (1990): “Anomalies: The Endowment Effect, Loss Aversion, and Status Quo Bias,” Journal of Economic Prospectives, 5(1), 193-206.

Kahneman, D., and A. Tversky (1979): "Prospect Theory: An Analysis of Decision Under Risk,” Econometrica, 47, 263-291.

Knetsch, J. L. (1989): "The Endowment Effect and Evidence of Nonreversible Indifference Curves,” American Economic Review, 79(5), 1277-1284. 
Knetsch, J. L. and J. A. Sinden (1984): "Willingness to Pay and Compensation Demanded: Expermental Evidence of an Unexpected Disparity in Measures of Value," Quarterly Journal of Economics, 99(3), 507-521.

Knez, P., V. L. Smith, and A. Williams (1985): "Individual Rationality, Market Rationality, and Value Estimation,” American Economic Review, 75, 397-402.

Levitt, S. D. (2004) “Testing Theories of Discrimination: Evidence from Weakest Link," Journal of Law and Economics, 47(2), 431-52.

List, J. (2004): "Neoclassical Theory Versus Prospect Theory: Evidence From the Marketplace,” Econometrica, 72(2), 615-625.

Metrick, A. (1995): “A Natural Experiment in 'Jeopardy!',” American Economic Review, 85(1), 240-253.

Myagkov, M. and C. R. Plott (1997): "Exchange Economies and Loss Exposure: Experiments Exploring Prospect Theory and Competitive Equilibria in Market Environments," American Economic Review, 87(5), 801-828.

Post, T., G. Baltussen, and M. Van den Assem (2006): "Deal or No Deal? Decision Making Under Risk in A Large-Payoff Game Show,” Tinbergen Institute Discussion Paper, accessed at http://www.tinbergen.nl/discussionpapers/06009.pdf on 22.02.2006

Rabin, M. (1998): “Psychology and Economics,” Journal of Economic Literature, 36(1), 11-46.

Rabin, M. (2000): “Risk Aversion and Expected-Utility Theory: A Calibration Theorem,” Econometrica, 68(5), 1281-1292.

Thaler, R. (1980): “Toward a Positive Theory of Consumer Choice," Journal of Economic Behavior and Organization, 1, 39-60.

Tversky, A., and D. Kahneman (1991): "Loss Aversion in Riskless Choice: A ReferenceDependent Model,” Quarterly Journal of Economics, 106, 1039-1061.

Tversky, A. and Kahneman, D. (1992): “Advances in prospect theory: Cumulative representation of uncertainty,” Journal of Risk and Uncertainty, 5, 297-323.

Samuelson, W. and R. Zeckhauser (1988): "Status Quo Bias in Decision Making," Journal of Risk and Uncertainty, 1(1), 7-59.

Shogren, J.F., S.Y. Shin, D.J. Hayes and J.B. Kliebenstein (1994): "Resolving Differences in Willingness to Pay and Willingness to Accept," American Economic Review, 84, 255-270.

Von Neumann, J. and Morgenstern, O. (1944): “Theory of Games and Economic Behavior," Princeton, Princeton University Press 


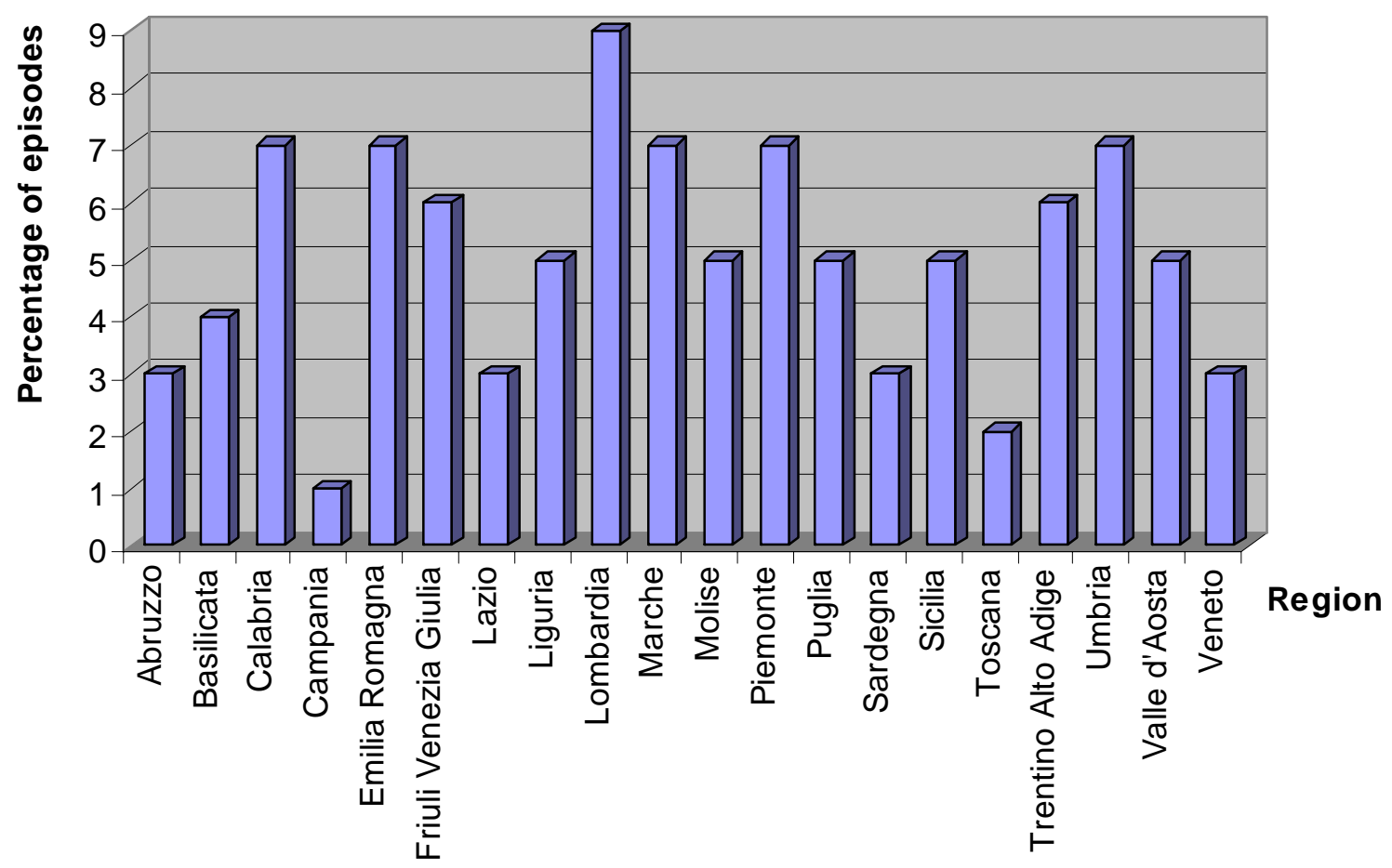

Figure 1 The Percentage of Episodes, Played by the Representatives of Each Italian Region 


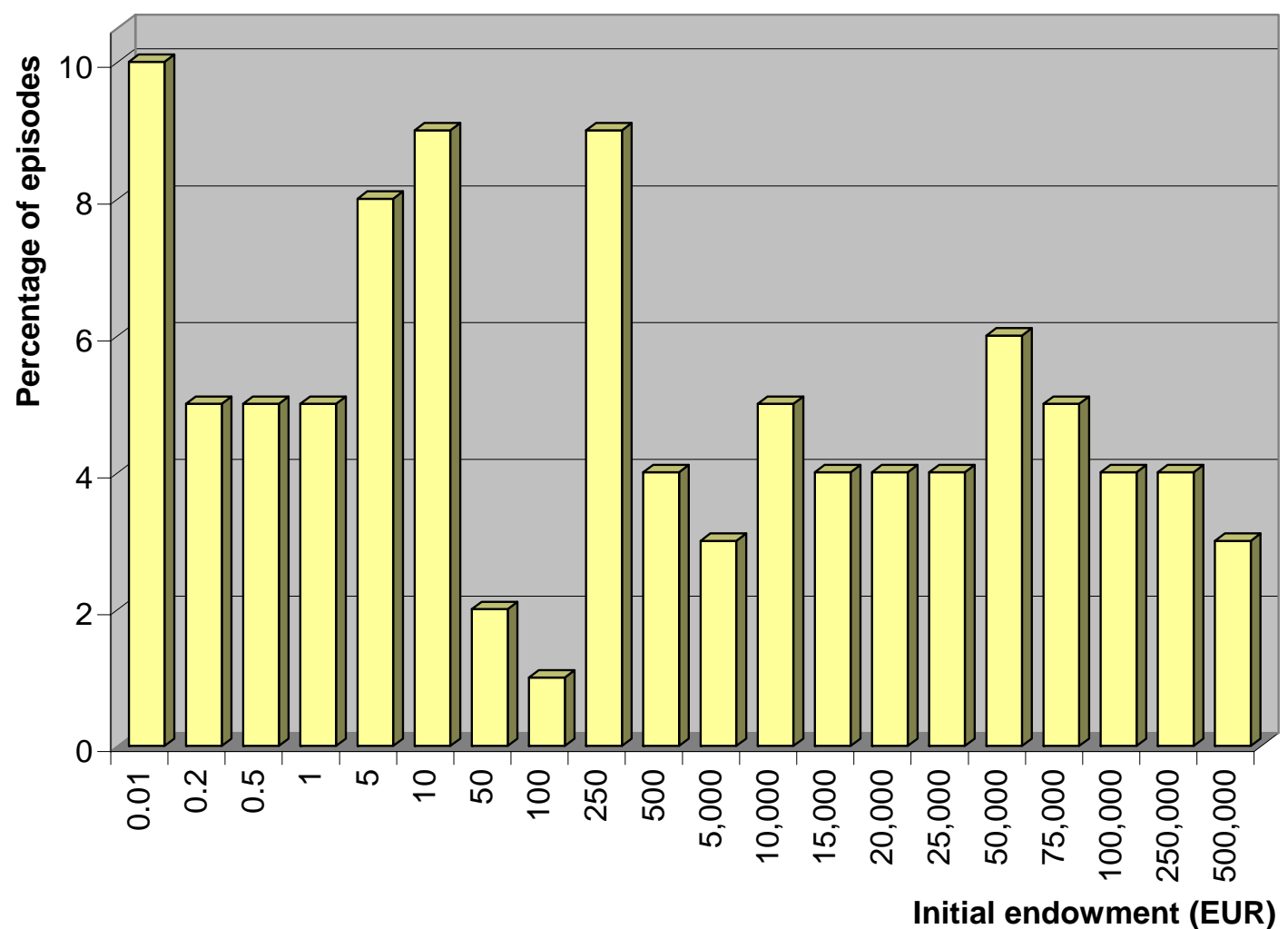

Figure 2 The Distribution of Initial Endowments Across One Hundred Episodes

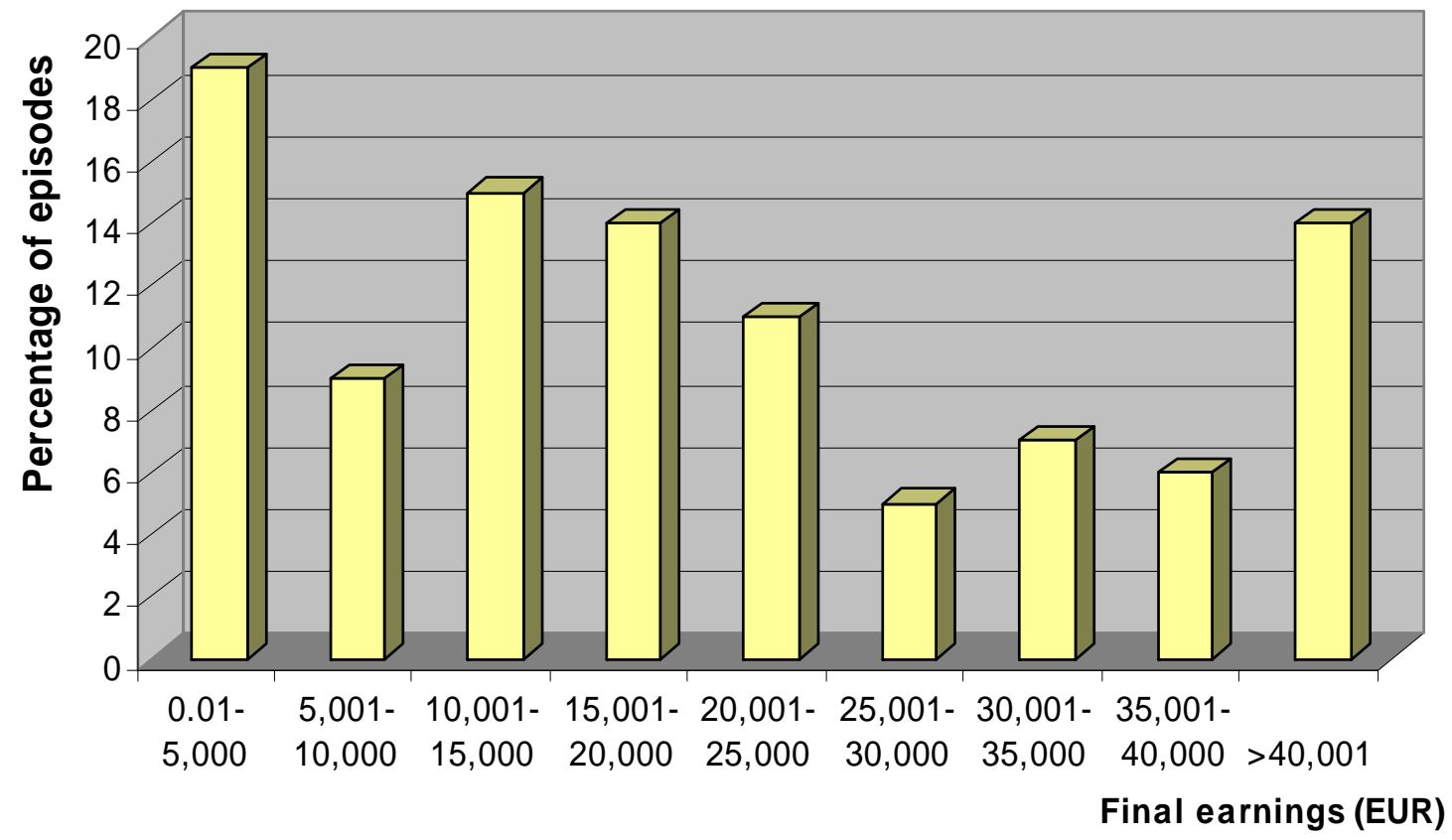

Figure 3 The Distribution of Final Earnings Across One Hundred Episodes 

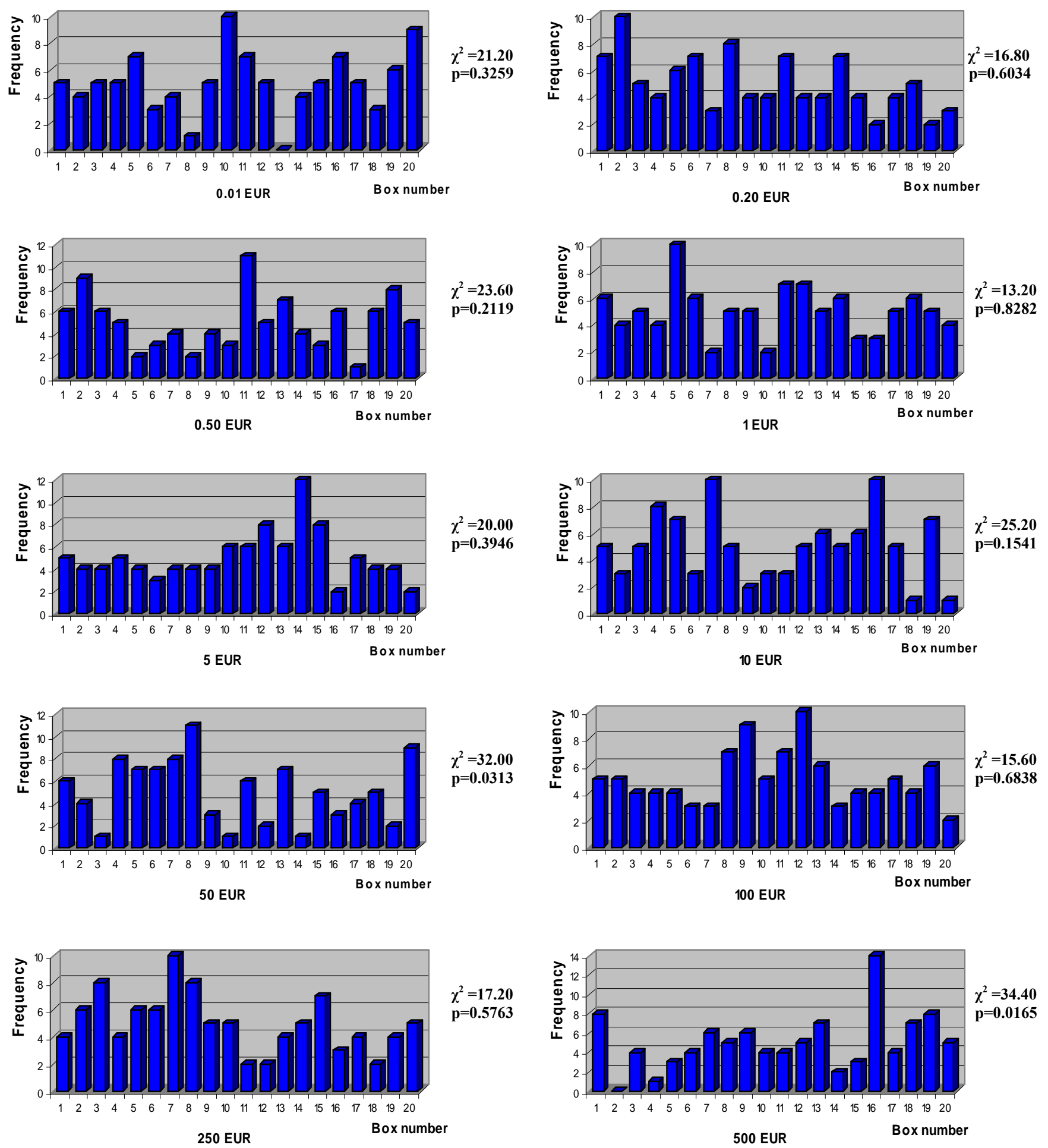

Figure 4 The Distribution of Prizes from 0.01 to 500 Euros Across Twenty Boxes 

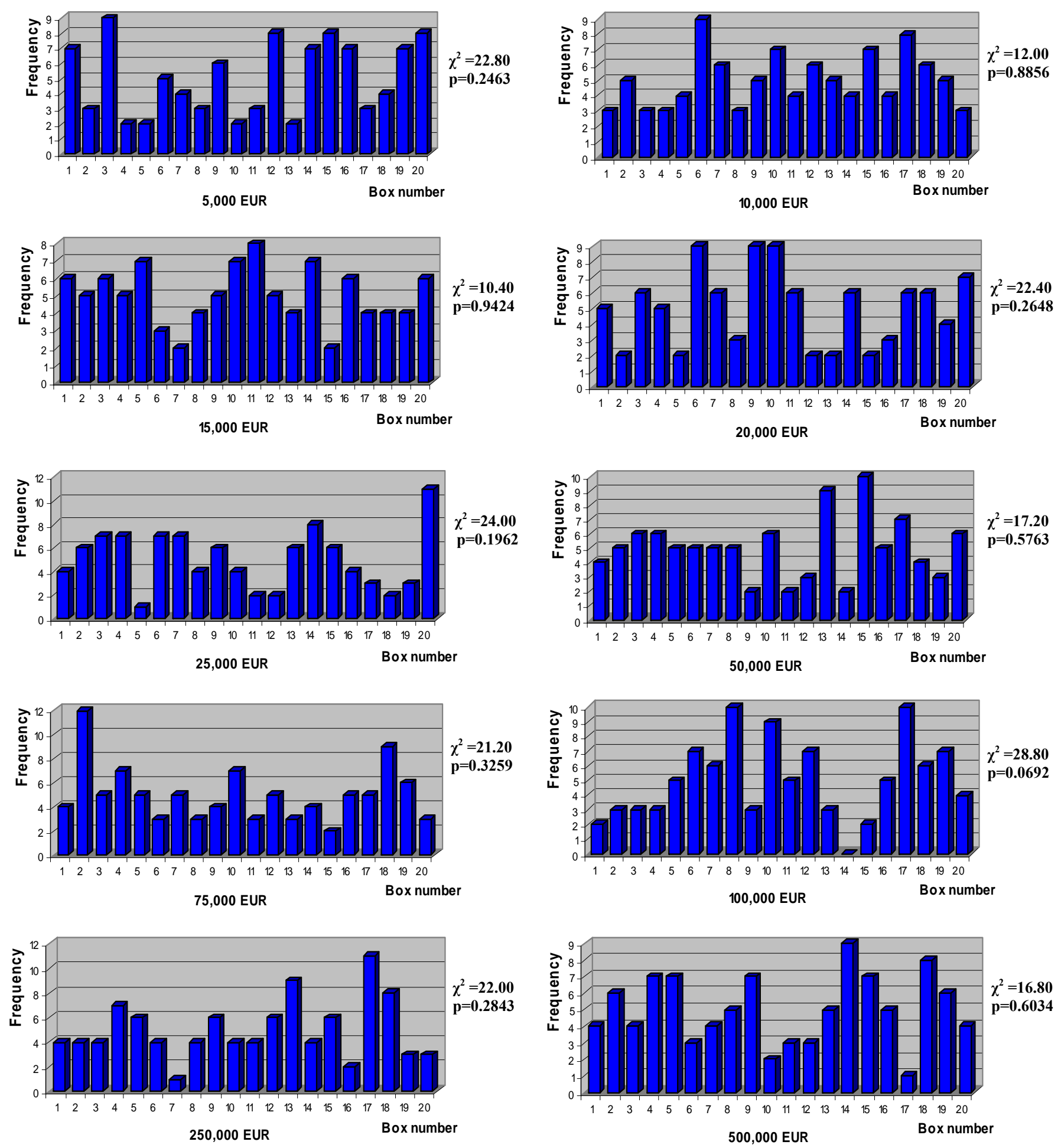

Figure 5 The Distribution of Prizes from 5,000 to 500,000 Euros Across Twenty Boxes 